\section{End-of-day Far-red Light Quality and Dose Requirements for Tomato Rootstock Hypocotyl Elongation}

\author{
Po-Lung Chia and Chieri Kubota ${ }^{1}$ \\ Division of Horticultural and Crop Sciences, School of Plant Sciences, The \\ University of Arizona, Tucson, AZ 85721-0036
}

Additional index words. phytochrome, LED, incandescent light, transplant production, grafting, controlled environment

\begin{abstract}
Plant morphology control is a critical technique in commercial greenhouse transplant production. Light treatment at the end of the day affects a phytochromeregulated response affecting plant height among other characteristics and has been studied by biologists for many years. Recognizing the need to produce long hypocotyls in vegetable grafting, effects of end-of-day far-red (EOD-FR) light on tomato rootstock hypocotyl elongation were investigated. Two commercial rootstock cultivars, Aloha (Solanum lycopersicum) and Maxifort (S. lycopersicum $\times$ S. habrochaites), were used for the experiments examining responses to EOD-FR light quality [red to far-red ratio (R/ FR)] and EOD-FR light dose in a greenhouse environment. In the EOD-FR light quality experiment using 'Aloha' seedlings, incandescent light $(\mathrm{R} / \mathrm{FR}=\mathbf{0 . 4 7})$ induced significant hypocotyl elongation $(20 \%)$ compared with the untreated control. Incandescent light with a spectral cut filter (reducing $R / F R$ to 0.05 ) induced a greater hypocotyl elongation $(44 \%)$ than unfiltered light, confirming the importance of use of light with a lower $R / F R$ (or purer FR) light source in EOD-FR treatments. In the experiment on EOD-FR light dose-response, hypocotyl elongation of both 'Aloha' and 'Maxifort' was increased by increasing FR intensity as well as FR treatment duration at a lower dose range. The dose saturation curve of hypocotyl length was well described using a Michaelis-Menten-type model with FR dose (in $\mathrm{mmol} \cdot \mathrm{m}^{-2} \cdot \mathrm{d}^{-1}$ ) as an independent variable. The model-based estimation of $90 \%$ saturating FR light dose for 'Aloha' and 'Maxifort' was 5 to 14 $\mathrm{mmol} \cdot \mathrm{m}^{-2} \cdot \mathrm{d}^{-1}$ and 8 to $15 \mathrm{mmol} \cdot \mathrm{m}^{-2} \cdot \mathrm{d}^{-1}$, respectively, although practical near saturation dose seems to be 2 to $4 \mathrm{mmol} \cdot \mathrm{m}^{-2} \cdot \mathrm{d}^{-1}$ for both cultivars. None of the EOD-FR treatments affected plant dry weight, stem diameter, or plastochron index. Hence, elongation was achieved without compromising growth and development. EOD-FR was shown to be an effective non-chemical means allowing transplant propagation industry to produce long hypocotyls for grafting use.
\end{abstract}

Phytochromes are photoreceptor proteins making possible the perception of the external light environment by plants. The light reception region within phytochrome is the chromophore that has two interconvertible isoforms with different peak light absorption spectra in the red [wavelengths of 600 to 700 $\mathrm{nm}(\mathrm{R})]$ and far-red [700 to $800 \mathrm{~nm}(\mathrm{FR})]$ regions (Hendricks et al., 1962; Siegelman et al., 1966). Irradiation with R or FR light changes the phytochrome isoform ratio and alters biochemical and physiological responses such as germination (Mancinelli et al., 1966), stem elongation, and pigment synthesis (Hendricks and Borthwick, 1967).

Red or FR light at the end of the day (photoperiod) is known to affect stem elongation (Blom et al., 1995; Decoteau et al., 1988;

Received for publication 11 June 2010. Accepted for publication 13 July 2010 .

CEAC paper number D-302430-01-10.

We thank Dennis Ray, Ursula Schuch, and Sam Wang for their valuable suggestions to improve the manuscript as well as statistical analyses and CCS, Inc. for providing the LED lighting system.

${ }^{1}$ To whom reprint requests should be addressed; e-mail ckubota@ag.arizona.edu.
Kasperbauer and Peaslee, 1973). Tomato seedlings with end-of-day (EOD) FR light treatment had a greater height and leaf length than those with EOD-R light treatment (Decoteau and Friend, 1991). EOD-FR lighting was also used in fundamental plant biology research, investigating the phytochrome signal transduction pathway in Arabidopsis thaliana, cucumber (Cucumis sativus), and other species such as aspen (Populus tremula $\times$ tremloides) in which stem elongation under EOD-FR was used as a positive test in identifying phytochrome genes and intermediate molecules such as gibberellic acid (Moe et al., 2003; Naganati et al., 1991; Olsen and Junttila, 2002).

Our study focuses on application of EODFR lighting in controlling morphology of tomato rootstock seedlings. Vegetable grafting has been widely used worldwide to obtain resistance to soilborne pathogens and pests (Kubota et al., 2008). Methyl bromide fumigation has been limited by the Montreal Protocol. As a result, alternatives such as grafting became increasingly viable. Producing seedlings with long hypocotyls is desired in vegetable grafting for the reasons described subsequently. The position of the graft union must be high enough to prevent the vulnerable scion from coming into direct contact and exposure with the soil. However, the tomato graft union is often below the cotyledons of rootstock seedlings, especially when rootstock axillary shoot growth needs to be avoided. Longer hypocotyl lengths of rootstock would both allow easier grafting and reduce the risk of scion exposure. Also, the authors are aware that commercial propagators often encounter inconsistencies in seedling morphology, possibly as a result of changes in light quality during twilight hours or light quality altered by the artificial lighting used in or near the propagation facilities. Hence, it may also be possible to use EOD light treatments as a means of increasing plant hypocotyl lengths as well as the consistency of seedling heights.

In this study, EOD-FR treatment was examined as a non-chemical means to extend hypocotyl length of tomato rootstock seedlings. Although supplemental lighting has limited use in commercial vegetable seedling production, EOD lighting may be more economically feasible than supplemental photosynthetic lighting as a result of its lower intensity requirements and shorter application duration. In the present study, we examined two critical questions that need to be answered for applications of EODFR treatment in vegetable seedling production: 1) light quality (R/FR ratio) and 2 ) minimum dose (intensity $\times$ duration) requirements to assure the maximum response of rootstock elongation.

Incandescent lamps emit light rich in FR (at $\approx 0.4$ to $0.5 \mathrm{R} / \mathrm{FR}$ ratio) and are often used for enriching FR light in plant growth chambers. They are also widely used for night break treatment (duration in hours) for modulating photoperiodic responses of floricultural species. In phytochrome studies, when incandescent lamps were used as the light source, they were always combined with a spectral cut filter to eliminate non-FR radiations. Lund et al. (2007) examined effects of R/FR ratios $(0.4$ and 0.7) in the EOD-FR treatment on stem elongation of chrysanthemum plants, showing a greater degree of stem elongation at a R/FR ratio of 0.4 than 0.7 . In our experiment, we compared the effects of EOD-FR lighting with a 0.05 to $0.47 \mathrm{R} / \mathrm{FR}$ ratio achieved by use of incandescent lamps and spectral filters.

In EOD experiments, FR or R light was provided at relatively low intensity for a short duration. For example, EOD-FR light intensity used in previously reported experiments varied from $0.8 \mu \mathrm{mol} \cdot \mathrm{m}^{-2} \cdot \mathrm{s}^{-1}$ (for Cucumis sativus; Moe et al., 2003) to $222 \mu \mathrm{mol} \cdot \mathrm{m}^{-2} \cdot \mathrm{s}^{-1}$ (for Vigna sinensis; Martinez-Garcia et al., 2000) for a lighting duration ranging from 4 min (for Pharbitis nil; Fredericq, 1964) to 30 min (for Cucumis sativus; Moe et al., 2003). Because phytochrome, as a photoreceptor, responds to the intensity (photon flux) as well as the spectral quality of light, understanding phytochrome kinetics (or dose-response) would help in selecting the necessary light intensity, quality, and treatment duration. Such understanding is especially important in horticultural applications where growers may consider use of light sources with optimized spectra such as light-emitting diodes 
(LEDs). However, only a limited number of plant species, including Avena sativa, Helianthus annuus, and Vigna radiate (Gorton and Briggs, 1982), Cucumis sativus (Gaba and Black, 1985), and Zea mays (Gorton and Briggs, 1980), were well studied for kinetic response to EOD-FR light treatments. As far as we know, there is no report on the level of saturation dose of EOD-FR light on tomato or its wild relatives. Therefore, we conducted an EOD-FR light dose experiment to find out the relationship between hypocotyl length and EOD-FR dose ( 1 to $8 \mathrm{mmol} \cdot \mathrm{m}^{-2} \cdot \mathrm{d}^{-1}$ ) using FR light of a $0.05 \mathrm{R} / \mathrm{FR}$ ratio. Dose was varied using both intensity and duration to find out whether the response was intensity- or duration-dependent.

\section{Materials and Methods}

Plant materials and growth conditions. The tomato rootstock cultivars Aloha (Solanum lycopersicum) (Ameriacan Takii, Salinas, $\mathrm{CA}$ ) and Maxifort (S. lycopersicum $\times$ $S$. habrochaites) (De Ruiter Seeds, Bergshenhoek, The Netherlands) were used in the experiments. 'Aloha' was used in the EODFR light quality experiment, whereas both 'Aloha' and 'Maxifort' were used for the EOD-FR dose experiment. Approximately 300 seeds of each cultivar were sown onto either moist vermiculite or moist filter paper in a plastic tray covered with a thin plastic film to select uniform seedlings. The seeded trays were placed for $2 \mathrm{~d}$ under darkness in growth chambers (Model 2015; VWR International, Cornelius, OR) controlled at 29 and $23{ }^{\circ} \mathrm{C}$ for 'Aloha' and 'Maxifort', respectively. Three to $5 \mathrm{~d}$ after seeding, uniform seedlings with 2 - to $3-\mathrm{cm}$ long radicles were transplanted into a 98cell seedling tray (tray size: $28 \mathrm{~cm} \times 55 \mathrm{~cm}$; one seedling per cell) filled with commercial substrate (SunGro Sunshine Professional Mix 3 , Bellevue, WA). The plants were placed in the greenhouse and irrigated daily throughout the treatment with nutrient solution (electrical conductivity 1.2 to $1.5 \mathrm{dS} \cdot \mathrm{m}^{-1}$, $\mathrm{pH} 6.3$ to 6.5 ) containing $104 \mathrm{NO}_{3}-\mathrm{N}, 23$ phosphorus, 177 potassium, 127 calcium, 30 magnesium, and 1 iron $(\mathrm{mg} / \mathrm{L})$ as well as micronutrients. When the cotyledons had fully expanded, 10 uniform seedlings were selected (planting area: $22.9 \times$ $15.2 \mathrm{~cm}$ ) for each treatment and cultivar.

The greenhouse (Tucson, AZ) used in the present experiments was covered by a doublelayered polyethylene roof and transparent polycarbonate walls and equipped with padand-fan cooling and overhead gas heating systems. Daytime and nighttime set points were 24 and $20^{\circ} \mathrm{C}$, respectively, and were controlled using a greenhouse environment control system (Argus, White Rock, British Columbia, Canada). A shade screen was deployed when solar radiation in the greenhouse exceeded $800 \mathrm{~W} \cdot \mathrm{m}^{-2}$.

End-of-day far-red light treatments. After 5 to $7 \mathrm{~d}$ from seeding, the rootstock seedlings were subject to daily EOD-FR light treatments. EOD treatments were initiated at 1830 HR at varied FR light intensities and durations (Table 1) everyday for $14 \mathrm{~d}$ inside an opaque cardboard box that prevented light contamination. The FR treatment boxes were loosely closed to allow natural ventilation so that the heat and gas (such as $\mathrm{CO}_{2}$ ) environment inside the box would not be largely different from outside while optically isolating the boxes. The plants were kept inside the boxes during the night and taken out of the boxes at dawn (0630 HR) of the next day. Air temperature within each treatment box was monitored using a thermocouple (Type T, 0.75 $\mathrm{mm}$ in diameter) and recorded using a CR23X data logger (Campbell Scientific, Logan, UT). Table 1 shows the light source, R/FR ratio, phytochrome photostationary state, FR light intensity, duration, and dosage examined in the experiments. Control treatments did not receive any EOD-FR treatment, although the plants were still kept in the same box without light from $1830 \mathrm{HR}$ to $0630 \mathrm{HR}$ to prevent light contamination from external light sources.

The light source used for EOD-FR was small incandescent light bulbs (input voltage: $2.5 \mathrm{~V}$; ACE \#9826009, Oakbrook, IL) distributed over a horizontal surface 22 to $25 \mathrm{~cm}$ above the plant canopy inside the EOD box. Tinted transparent acrylic sheets (Ridout Plastics Plexiglas blue, San Diego, CA; $0.32 \mathrm{~mm}$ thick, \#2424) were used as a spectral cut filter to remove a significant portion of $\mathrm{R}$ light (600 to $700 \mathrm{~nm}$ ) and lower the R/FR ratio from 0.47 (unfiltered) to 0.05 . We expressed the light quality using a phytochrome photostationary state $\left(\mathrm{P}_{\mathrm{fr}} / \mathrm{P}_{\text {total }}\right)$ (Sager et al., 1988) in addition to a simple parameter $\mathrm{R} / \mathrm{FR}$ ratio. When different light sources are used to modulate photochrome, use of $\mathrm{P}_{\mathrm{fr}} / \mathrm{P}_{\text {total }}$ is more appropriate because it represents the relative amount of phytochromes in their active isoform $\left(\mathrm{P}_{\mathrm{fr}}\right)$ compared with total phytochromes $\left(\mathrm{P}_{\text {total }}\right)$ in the plant. Filtered incandescent light had lower $\mathrm{P}_{\mathrm{fr}} / \mathrm{P}_{\text {total }}(0.17$ to $0.20)$ than did the unfiltered treatment $(0.61)$. A layer of black plastic shade screen and dimmers (TT-300-NLH; Lutron Electronics Co., Coopersburg, PA) were used to reduce the light intensity as needed for incandescent lamps. For the FR light dose-response experiment, an LED panel (ISL series; CCS Inc., Kyoto, Japan) mounted with R and FR LEDs (peak wavelengths at 660 and $735 \mathrm{~nm}$, respectively) attached to a digital controller (CCS Inc.) was also used as a light source to provide the highest FR light intensity. Red LEDs were also used at a low intensity to achieve the same $\mathrm{R} / \mathrm{FR}$ ratio of 0.05 as the incandescent-based light source.

Our EOD-FR dose experiment examined a dose range of 1 to $8 \mathrm{mmol} \cdot \mathrm{m}^{-2} \cdot \mathrm{d}^{-1}$, varying both treatment duration (3 to $24 \mathrm{~min}$ ) as well as FR light intensity (1.4 to $40.0 \mu \mathrm{mol} \cdot \mathrm{m}^{-2} \cdot \mathrm{s}^{-1}$ ) (Table 1). There were five treatments and an untreated control in EOD-FR light dose experiment. The treatments were labeled S01T12D1, S01T24D2, S03T12D2, S03T24D4, and S40T03D8 with numbers followed by letter $\mathrm{S}$ representing the FR photon flux $\left(\mu \mathrm{mol} \cdot \mathrm{m}^{-2} \cdot \mathrm{s}^{-1}\right), \mathrm{T}$ representing duration of the treatment $(\mathrm{min})$, and $\mathrm{D}$ representing the dose $\left(\mathrm{mmol} \cdot \mathrm{m}^{-2} \cdot \mathrm{d}^{-1}\right)$. Hence, S01T12D1 would be the treatment in which FR photon flux was $1 \mu \mathrm{mol} \cdot \mathrm{m}^{-2} \cdot \mathrm{s}^{-1}$, treatment duration was $12 \mathrm{~min}$, and dose was $1 \mathrm{mmol} \cdot \mathrm{m}^{-2} \cdot \mathrm{d}^{-1}$. S00T00D0 represents the untreated control.

$\mathrm{R} / \mathrm{FR}$ ratio and FR light intensity of the light sources in both experiments (Table 1) were measured using a spectroradiometer (Model PS-100; Apogee Instruments Inc., Logan, UT). Averages of five readings were

Table 1. Light source, red to far-red ratio (R/FR), phytochrome photostationary state $\left(\mathrm{P}_{\mathrm{fr}} / \mathrm{P}_{\text {total }}\right)$, far-red light intensity (photon flux), duration and far-red dose applied in the end-of-day far-red (EOD-FR) light quality, and dose experiments.

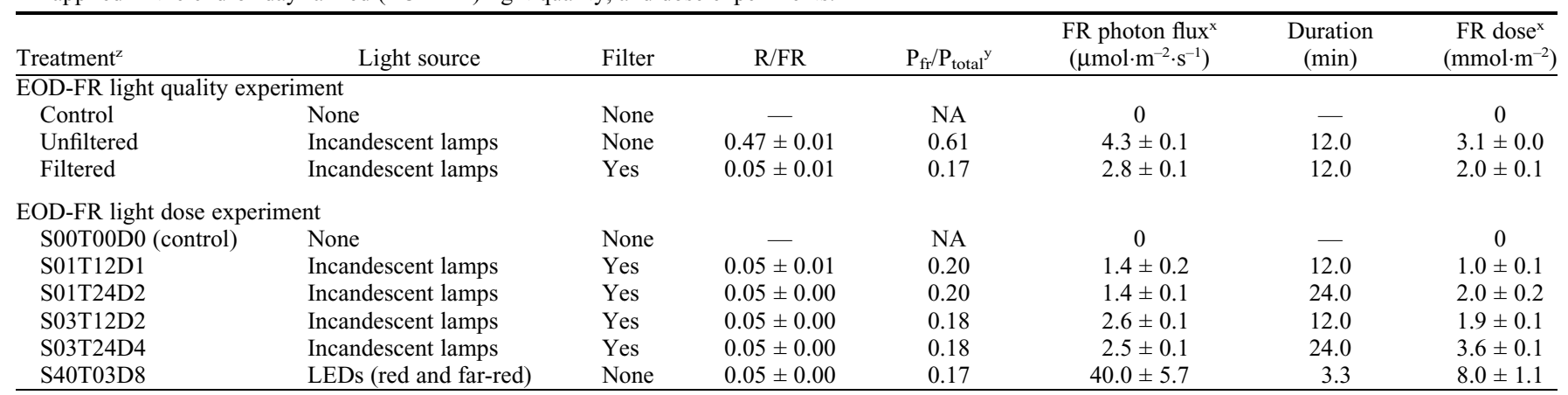

${ }^{2}$ Control treatments were not given EOD-FR. Numbers followed by letter S representing the FR photon flux $\left(\mu \mathrm{mol} \cdot \mathrm{m}^{-2} \cdot \mathrm{s}^{-1}\right), \mathrm{T}$ representing duration of the treatment $(\mathrm{min})$, and D representing the dose $\left(\mathrm{mmol} \cdot \mathrm{m}^{-2} \cdot \mathrm{d}^{-1}\right)$.

${ }^{y}$ Phytochrome photostationary state (Sager et al., 1988).

${ }^{x}$ Averages of repeated experiments are shown. Dose was the product of far-red photon flux and duration of the treatment.

LEDs $=$ light-emitting diodes; NA $=$ not applicable 
recorded at plant canopy height across the plant growing area $(23 \times 15 \mathrm{~cm})$. Three measurements were carried out on Days 1, 7, and 14 of the treatment to assure the constant light environments during the experiment.

Plant measurements. After $14 \mathrm{~d}$ of EODFR treatment, lengths of hypocotyl and epicotyl were measured using a stainless steel ruler. Stem diameter was measured using an electronic digital caliper, whereas stem (hypocotyl and epicotyl) and leaf fresh weights of the seedlings were measured using an electronic balance. After drying at $80^{\circ} \mathrm{C}$ for $3 \mathrm{~d}$, stem dry weight and leaf dry weight were also measured. Plastochron index (Erickson and Michelini, 1957) was computed to quantify the plant developmental stage using the following equation:

Plastochron Index $=n+\frac{\log L_{n}-\log R}{\log L_{n}-\log L_{n+1}}$

where $n$ is the number of leaves with lengths (from the nodal end of petiole to the tip of the youngest leaflet) greater than $R$, the reference length $(10 \mathrm{~mm}) . L_{n}$ is the length of leaf $n$, whereas $L_{n+1}$ is the length of the first leaf younger than leaf $n$.

Saturation far-red light dose analysis. Because EOD-FR was perceived by the plants through phytochrome receptors present in limited amounts in the plant, a MichaelisMenten model used often to illustrate enzyme reaction was applied to represent the relationship between FR dose and hypocotyl elongation. To find the saturation FR light dose, the data were fitted with the following MichaelisMenten-type model for each of the three repeated experiments:

$$
H_{L}=\frac{V_{\max } \times D}{K_{M}+D}+H_{o}
$$

where $H_{L}$ is hypocotyl length (mm); $V_{\max }$ is maximum increase in hypocotyl length $(\mathrm{mm}) ; D$ is the FR dose $\left(\mathrm{mmol} \cdot \mathrm{m}^{-2} \cdot \mathrm{d}^{-1}\right) ; K_{M}$ is the Michaelis-Menten parameter representing the FR dose to reach $50 \%$ of the maximum hypocotyl elongation; and $H_{o}$ is the hypocotyl length $(\mathrm{mm})$ of the untreated control $(D=$ $\left.0 \mathrm{mmol} \cdot \mathrm{m}^{-2} \cdot \mathrm{d}^{-1}\right)$. The model parameters were estimated using a non-linear regression program (JMP; SAS Institute, Cary, NC) and were used to compute $F D_{90}$, the near-saturating FR light dose that would provide $90 \%$ of $V_{\max }$. $F D_{90}$ would essentially be nine times of $K_{M}$ as the $V_{\max }$ multiplier in Eq. [2] becomes 0.9 .

Experimental design. The EOD light quality experiment was conducted twice for 12 to 26 Sept. 2008 and 15 to 28 Oct. 2008. Each repetition consisted of an untreated control and two treatments of different R/ FR (0.47 and 0.05). One EOD-FR treatment box was used for each treatment. The FR light dose-response experiment was conducted three times for 14 to 27 Mar. 2009, 8 to 21 Apr. 2009, and 1 to 14 May 2009 using a randomized block design. Within each experimental period, the treatments were repeated three times and grouped into three blocks (except for the treatment S40T03D8, one block per each experiment). Positions of the three blocks as well as the treatments within the block were randomized. Mean values of each plant growth parameter (length, width, plastochron index, and weight) were pooled together and analyzed for mean separation because analysis of variance did not show an interaction in either month or block (for EOD-FR dose experiments), except for the non-linear regression parameters showing interaction of month and dose. The results were analyzed using JMP (SAS Institute).

\section{Results and Discussion}

End-of-day far-red light quality effects on plants. An EOD-FR light treatment at $0.05 \mathrm{R} /$ FR ratio (filtered incandescent lamps) significantly increased hypocotyl length compared with that at $\mathrm{R} / \mathrm{FR}$ ratio of 0.47 (unfiltered) or the untreated control. 'Aloha' seedling hypocotyl length was increased by $8 \mathrm{~mm}(20 \%)$ and $18 \mathrm{~mm}(44 \%)$ for R/FR ratio of 0.47 and 0.05 , respectively, compared with that in the control (Table 2). The spectral filter used in the experiment reduced the FR light intensity by $35 \%$ (Table 1 ), but hypocotyl elongated at a greater extent under filtered incandescent lamps (low R/FR and low FR intensity) than unfiltered ones (high R/FR and high FR intensity). Relative insensitivity to the FR intensity was presumably the result of the higher R/FR ratio as well as saturation FR dose $\left(2.0\right.$ to $\left.3.1 \mathrm{mmol} \cdot \mathrm{m}^{-2} \cdot \mathrm{d}^{-1}\right)$ used in the experiment, which was validated in the following dose experiment. Seedling epicotyl lengths were significantly increased by 15 $\mathrm{mm}(42 \%)$ for a $\mathrm{R} / \mathrm{FR}$ ratio of 0.05 , but not for a $\mathrm{R} / \mathrm{FR}$ ratio of 0.47 . As a result of the stem elongation, stem fresh weight also increased significantly by $0.109 \mathrm{~g}(36 \%)$ and $0.239 \mathrm{~g}$ (79\%) for R/FR of 0.47 and 0.05 , respectively, compared with that in the control. Stem dry weight, however, did not show any significant difference between the treatments. The fresh and dry weights of the leaf, stem diameter, and plastochron index were also not significantly affected by the treatment (Table 2 ). In addition to 'Aloha', 'Maxifort' seedlings were grown in Oct. 2008 for a preliminary analysis, in which the same general trend was observed (data not shown)

Similar observations of enhanced stem elongation under EOD-FR were reported by other research groups using light with a lower R/FR ratio using various plant species (Hatt Graham and Decoteau, 1997; Lund et al., 2007; Martinez-Garcia et al., 2000; Rajapakse et al., 1993; Xiong et al., 2002). Decoteau and Friend (1991), however, found no significant difference in tomato plant height (sum of hypocotyl and epicotyl lengths) between the untreated control and the EOD-FR-treated plants (15 $\mathrm{min}$ at $\left.43.7 \mu \mathrm{mol} \cdot \mathrm{m}^{-2} \cdot \mathrm{s}^{-1}\right)$. The difference could be attributed to the plant age, because Decoteau and Friend (1991) applied EOD-FR treatment $18 \mathrm{~d}$ after seeding, whereas we did as early as $5 \mathrm{~d}$ after seeding in our experiment.

Lund et al. (2007) demonstrated that Chrysanthemum $\times$ morifolium plant height increased with increasing $\mathrm{R} / \mathrm{FR}$ ratio of EOD treatments by testing $0.4,0.7$, and 2.4 $\mathrm{R} / \mathrm{FR}$ ratios using two different approaches. When R/FR ratio was the lowest (0.4), varying the actual FR or R intensity did not affect the stem elongation, whereas there was a significant effect of FR or R intensity at greater $\mathrm{R} / \mathrm{FR}$ ratios. Together with our results, it is confirmed that use of a purer FR light source (with lower R/FR ratio) would more effectively increase the plant height and hypocotyl lengths, offering flexibility in selecting the actual light intensities as long as the FR dose requirement is met. LEDs are a potential light source to be used in EOD-FR applications, although the price of FR LEDs is relatively higher than that of widely used $R$ LEDs, mainly as a result of their currently limited market (CCS, Inc., personal communication), because FR is a unique light quality for plant responses but not useful in industrial applications for humans. Together with the recent increasing environmental concern and thereby possible future limitation of incandescent lamps, greater demand is expected for FR LEDs in horticultural applications, which may lead to a significant reduction of FR LED price. Until then, a practical light source for EOD-FR may be the combination of incandescent lamps and spectral filters, like we used in our experiment.

End-of-day far-red dose effects on plants. EOD-FR dose treatments affected only hypocotyl length in both rootstock cultivars ('Aloha' and 'Maxifort'). Epicotyl length (64 to $77 \mathrm{~cm}$ and 68 to $77 \mathrm{~cm}$ ), stem diameter ( 3.33 to $3.42 \mathrm{~mm}$ and 3.25 to $3.40 \mathrm{~mm}$ ), plastochron index (5.11 to 5.27 and 6.06 to 6.17), stem fresh weight (0.934 to $1.159 \mathrm{~g}$ and 0.696 to $0.866 \mathrm{~g}$ ), stem dry weight ( 0.056 to $0.066 \mathrm{~g}$ and 0.048 to $0.056 \mathrm{~g}$ ), leaf fresh weight (1.324 to $1.453 \mathrm{~g}$ and 1.618 to 1.671 $\mathrm{g}$ ), and leaf dry weight ( 0.181 to $0.201 \mathrm{~g}$ and 0.221 to $0.236 \mathrm{~g}$ ), respectively, did not show significant differences between the EOD-FR treatments (data not shown).

Hypocotyl length significantly increased by EOD-FR treatments regardless of FR light intensity and duration compared with the untreated control (Table 3). Increase in hypocotyl length was $12 \%$ to $24 \%$ for 'Aloha' and $17 \%$

Table 2. Hypocotyl length (HL), epicotyl length (EL), stem diameter (SD), plastochron index (PI), stem and leaf fresh, and dry weights (FW, DW) for 'Aloha' tomato rootstock seedlings as affected by endof-day far-red light treatment and the light quality (R/FR ratio).

\begin{tabular}{lccccccccc}
\hline Treatment & R/FR & HL $(\mathrm{mm})$ & EL $(\mathrm{mm})$ & SD $(\mathrm{mm})$ & PI & $\begin{array}{c}\text { Stem FW } \\
(\mathrm{g} / \text { plant })\end{array}$ & $\begin{array}{c}\text { Leaf FW } \\
(\mathrm{g} / \text { plant })\end{array}$ & $\begin{array}{c}\text { Stem DW } \\
(\mathrm{g} / \mathrm{plant})\end{array}$ & $\begin{array}{c}\text { Leaf DW } \\
(\mathrm{g} / \mathrm{plant})\end{array}$ \\
\hline Control & $\mathrm{NA}$ & $41 \mathrm{c}^{\mathrm{z}}$ & $36 \mathrm{~b}$ & $2.4 \mathrm{a}$ & $4.2 \mathrm{a}$ & $0.301 \mathrm{c}$ & $0.458 \mathrm{a}$ & $0.015 \mathrm{a}$ & $0.042 \mathrm{a}$ \\
Unfiltered & 0.47 & $49 \mathrm{~b}$ & $41 \mathrm{ab}$ & $2.5 \mathrm{a}$ & $4.1 \mathrm{a}$ & $0.410 \mathrm{~b}$ & $0.514 \mathrm{a}$ & $0.019 \mathrm{a}$ & $0.045 \mathrm{a}$ \\
Filtered & 0.05 & $59 \mathrm{a}$ & $51 \mathrm{a}$ & $2.6 \mathrm{a}$ & $4.1 \mathrm{a}$ & $0.540 \mathrm{a}$ & $0.559 \mathrm{a}$ & $0.024 \mathrm{a}$ & $0.050 \mathrm{a}$ \\
\hline
\end{tabular}

${ }^{\mathrm{z}}$ Analysis of variance-protected mean separation by least significant difference $(P<0.05)$.

$\mathrm{NA}=$ not applicable. 
to $34 \%$ for 'Maxifort'. Hypocotyl length was increased by increasing the intensity of FR light at the shorter treatment duration for both cultivars. That is, the increase of hypocotyl length was $6 \mathrm{~mm}(12 \%$ to $17 \%)$ at 1.4 $\mu \mathrm{mol} \cdot \mathrm{m}^{-2} \cdot \mathrm{s}^{-1}$ (S01T12D1) and 10 to $11 \mathrm{~mm}$ ( $22 \%$ to $29 \%$ ) at $2.6 \mu \mathrm{mol} \cdot \mathrm{m}^{-2} \cdot \mathrm{s}^{-1} \mathrm{FR}$ light intensity (S03T12D2) compared with the untreated control (S00T00D0). However, no significant difference was observed between 1.4 and $2.5 \mu \mathrm{mol} \cdot \mathrm{m}^{-2} \cdot \mathrm{s}^{-1}$ FR light intensity with the 24-min treatment duration (S01T24D2 and S03T24D2).

Increasing duration of EOD-FR also increased hypocotyl length at the lower FR light intensity for both cultivars (Table 3 ). Under $1.4 \mu \mathrm{mol} \cdot \mathrm{m}^{-2} \cdot \mathrm{s}^{-1}$ FR light intensity, the increase of hypocotyl length was $6 \mathrm{~mm}$ $(12 \%$ to $17 \%)$ with the 12 -min treatment duration (S01T12D1) and 11 to $12 \mathrm{~mm} \mathrm{(22 \%}$ to $34 \%$ ) with the 24-min treatment duration (S01T24D2) compared with the untreated control. However, no significant difference was observed between the treatments with 12-min and 24-min FR treatment durations under 2.5 to $2.6 \mu \mathrm{mol} \cdot \mathrm{m}^{-2} \cdot \mathrm{s}^{-1} \mathrm{FR}$ light intensity (S03T12D2 and S03T24D4).

When the same cumulative FR light dose was applied using different combinations of light intensity $\left(1.4\right.$ or $\left.2.6 \mu \mathrm{mol} \cdot \mathrm{m}^{-2} \cdot \mathrm{s}^{-1}\right)$ and duration (24 or $12 \mathrm{~min}$, respectively) (S01T24D2 and S03T12D2 treatments), hypocotyl elongation was not significantly different between treatments (Table 3). This suggests that EOD-FR dose was the primary factor determining the magnitude of hypocotyl elongation. For FR doses above $2 \mathrm{mmol} \cdot \mathrm{m}^{-2} \cdot \mathrm{d}^{-1}$ (S01T24D2, S03T12D2, S03T24D4, and S40T03D8), increasing dose did not correspond to increasing length of hypocotyl for either cultivar. The combination of highest FR light intensity $\left(40 \mu \mathrm{mol} \cdot \mathrm{m}^{-2} \cdot \mathrm{s}^{-1}\right)$ and shortest duration $(3 \mathrm{~min}$ ) produced the same hypocotyl length as other treatments ( 2 or 4 $\left.\mathrm{mmol} \cdot \mathrm{m}^{-2} \cdot \mathrm{d}^{-1}\right)$ for both cultivars. These results demonstrate that FR light intensity and duration can be more flexibly selected as long as the dose reaches the saturation point. Therefore, a combination of a higher output light source such as LEDs with a shorter duration than those examined in our experiment may be applicable as long as reciprocity characteristics do not fail. Similarly, use of an

Table 3. Hypocotyl length of 'Maxifort' and 'Aloha' tomato rootstock seedlings as affected by the end-of-day far-red light intensity and duration.

\begin{tabular}{lcc}
\hline & $\begin{array}{c}\text { 'Maxifort' } \\
\text { hypocotyl } \\
\text { 1ength }(\mathrm{mm})\end{array}$ & $\begin{array}{c}\text { 'Aloha' } \\
\text { hypocotyl } \\
\text { 1ength (mm) }\end{array}$ \\
Treatment $^{\mathrm{y}}$ & $35 \mathrm{c}^{\mathrm{z}}$ & $49 \mathrm{c}$ \\
S00T00D0 & $41 \mathrm{~b}$ & $55 \mathrm{~b}$ \\
S01T12D1 & $47 \mathrm{a}$ & $60 \mathrm{a}$ \\
S01T24D2 & $45 \mathrm{a}$ & $60 \mathrm{a}$ \\
S03T12D2 & $47 \mathrm{a}$ & $61 \mathrm{a}$ \\
S03T24D4 & $47 \mathrm{a}$ & $60 \mathrm{ab}$ \\
\hline
\end{tabular}

${ }^{\mathrm{z}}$ Analysis of variance-protected mean separation by least significant difference $(P<0.05)$.

${ }^{y}$ Numbers followed by letter $S$ representing the FR photon flux $\left(\mu \mathrm{mol} \cdot \mathrm{m}^{-2} \cdot \mathrm{s}^{-1}\right)$, T representing duration of the treatment ( $\mathrm{min}$ ), and D representing the dose $\left(\mathrm{mmol} \cdot \mathrm{m}^{-2} \cdot \mathrm{d}^{-1}\right)$. S00T00D0 is the untreated control. oscillating aluminum parabolic reflector used for high-pressure sodium lamps [such as one examined by Blanchard and Runkle (2010) to control flowering] may be combined with such high-output FR LEDs to achieve a necessary saturation dose with a limited number of fixtures per greenhouse production space. As such, our data can be used to develop effective application strategies of EOD-FR dose for hypocotyl elongation. Nevertheless, those strategies need to be tested before attempting the use of EOD-FR in commercial propagation.

Saturating far-red dose for hypocotyl elongation. To better quantify the relationship between seedling hypcotoyl length and
FR light dose, the Michaelis-Menten-type model [Eq. (2)] was applied. The model described the dose-response satisfactorily and the parameters were obtained individually for March, April, and May (Figs. 1 and 2). Similar saturation responses to FR light dose were observed in previous experiments regarding anthocyanin degradation, mesocotyl, and coleoptile elongation (e.g., Gorton and Briggs, 1980, 1982). In these experiments, different levels of FR dose were achieved by either varying treatment duration alone (Gorton and Briggs, 1980) or with a combination of varying both treatment duration and FR intensity (Gorton and Briggs, 1982).
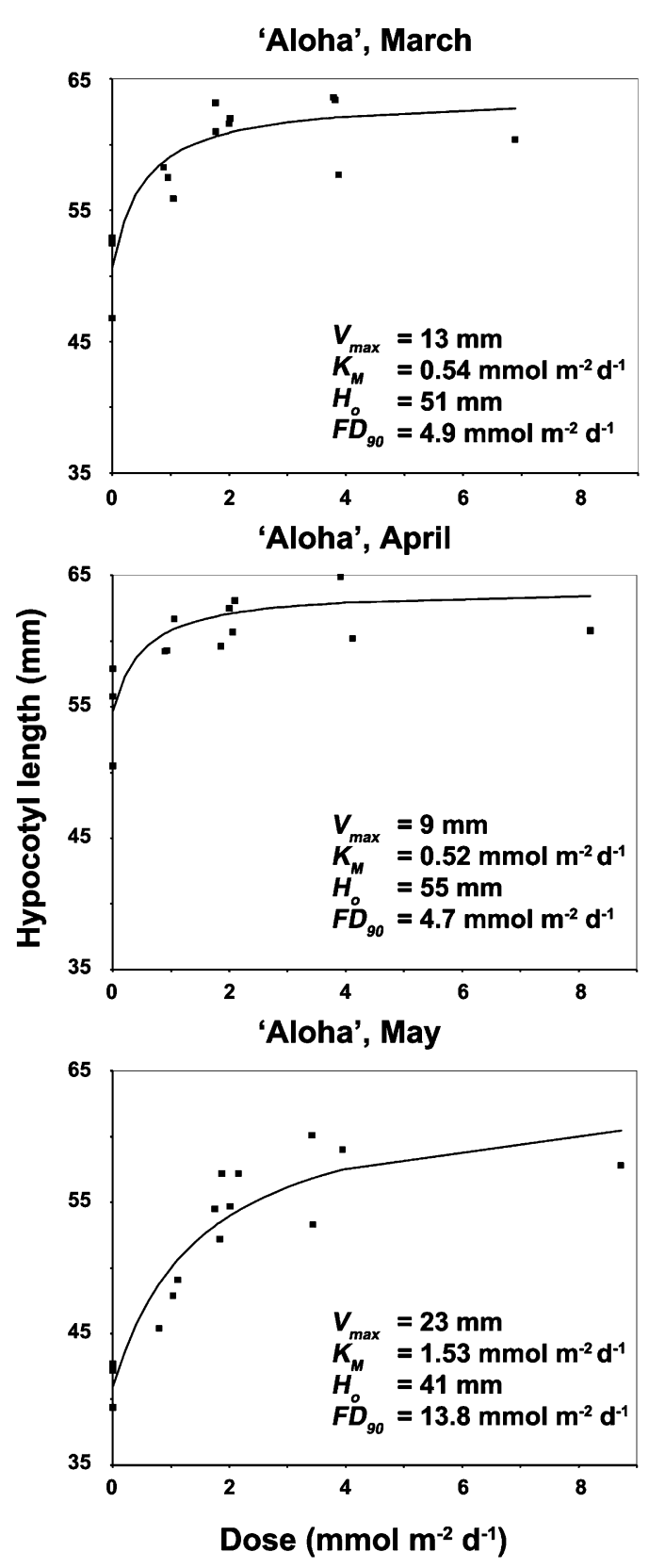

Fig. 1. End-of-day far-red (FR) light dose-responses of 'Aloha' tomato rootstock hypocotyl elongation obtained for three different months of experiment (March, April, and May 2009). Data were fitted with a Michaelis-Menten-type model $H_{L}=\left(V_{\max } \times D\right) /\left(K_{M}+D\right)+H_{0}$, where $H_{L}, V_{\max }, D, K_{M}$, and $H_{0}$ represent hypocotyl length (millimeters, shown in vertical axis), maximum increase in hypocotyl length at saturation dose, far-red light dose $\left(\mathrm{mmol} \cdot \mathrm{m}^{-2} \cdot \mathrm{d}^{-1}\right.$, shown in horizontal axis), MichaelisMenten parameter, and hypocotyl length of untreated control $(D=0)$, respectively. $F D_{90}$ was estimated as the near-saturating FR light dose that would provide $90 \%$ of $V_{\max }$. 

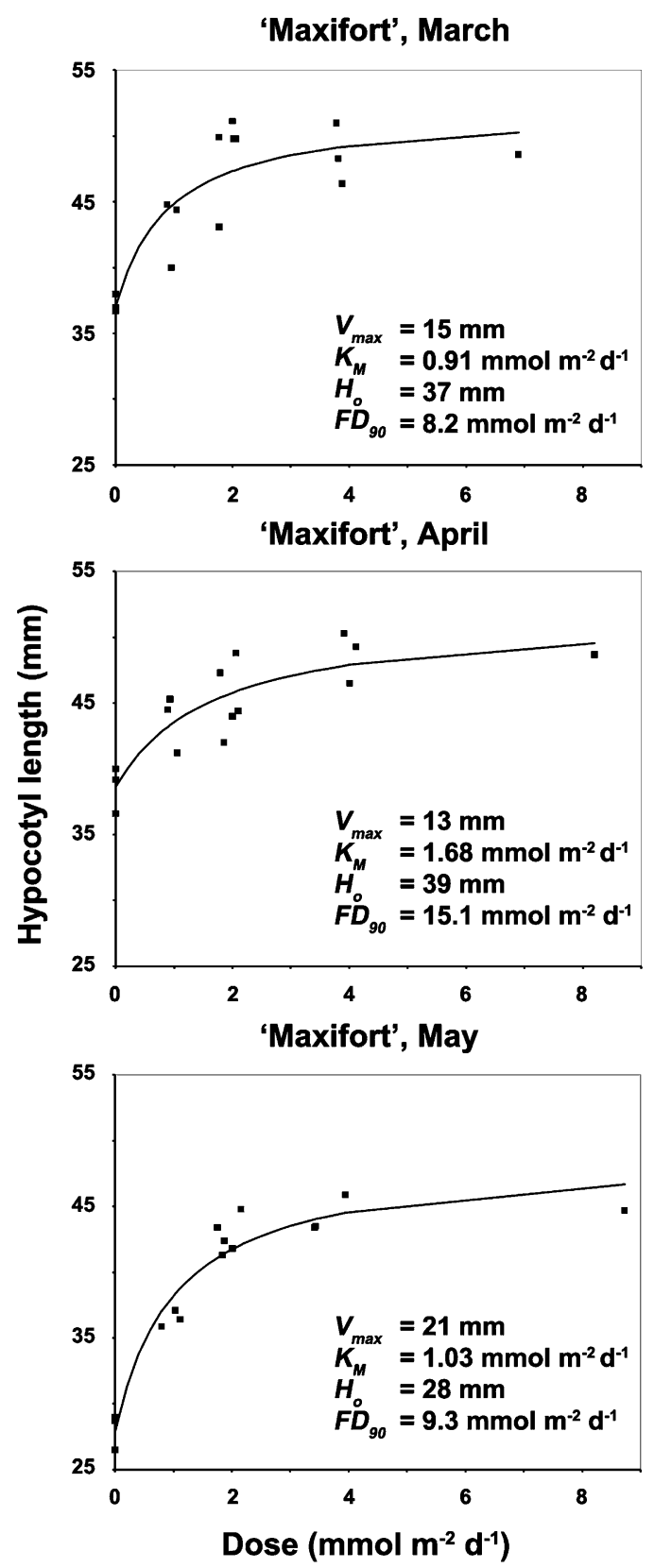

Fig. 2. End-of-day far-red light dose-responses of 'Maxifort' tomato rootstock hypocotyl elongation obtained for three different months of experiment (March, April, and May 2009). Data were fitted with a Michaelis-Menten-type model $H_{L}=\left(V_{\max } \times D\right) /\left(K_{M}+D\right)+H_{0}$, where $H_{L}, V_{\max }, D, K_{M}$, and $H_{0}$ represent hypocotyl length (millimeters, shown in vertical axis), maximum increase in hypocotyl length at saturation dose, far-red (FR) light dose $\left(\mathrm{mmol} \cdot \mathrm{m}^{-2} \cdot \mathrm{d}^{-1}\right.$, shown in horizontal axis), MichaelisMenten parameter, and hypocotyl length of untreated control $(D=0)$, respectively. $F D_{90}$ was estimated as the near-saturating FR light dose that would provide $90 \%$ of $V_{\max }$.

In the present experiment, the model parameters $V_{\max }, K_{M}$, and $H_{0}$ and estimated $F D_{90}$ were varied by cultivar and month (Figs. 1 and 2). $V_{\max }$, the maximum increase in hypocotyl length, was 9 to $23 \mathrm{~mm}$ and 13 to $21 \mathrm{~mm}$ for 'Aloha' and 'Maxifort', respectively. The $K_{M}$ and $F D_{90}$ for 'Aloha' were increased from $\approx 0.5 \mathrm{mmol} \cdot \mathrm{m}^{-2} \cdot \mathrm{d}^{-1}$ and $5 \mathrm{mmol} \cdot \mathrm{m}^{-2} \cdot \mathrm{d}^{-1}$ in both March and April to $1.53 \mathrm{mmol} \cdot \mathrm{m}^{-2} \cdot \mathrm{d}^{-1}$ and $14 \mathrm{mmol} \cdot \mathrm{m}^{-2} \cdot \mathrm{d}^{-1}$ in May, respectively. In 'Maxifort', $K_{M}$ and $F D_{90}$ were relatively higher in April (1.68 $\mathrm{mmol} \cdot \mathrm{m}^{-2} \cdot \mathrm{d}^{-1}$ and $\left.15.1 \mathrm{mmol} \cdot \mathrm{m}^{-2} \cdot \mathrm{d}^{-1}\right)$ than in March and May ( 0.9 to $1.0 \mathrm{mmol} \cdot \mathrm{m}^{-2} \cdot \mathrm{d}^{-1}$ and 8.2 to $9.3 \mathrm{mmol} \cdot \mathrm{m}^{-2} \cdot \mathrm{d}^{-1}$, respectively).
We noticed that the hypocotyl lengths at $D=0\left(H_{0}\right)$ was relatively shorter in May than those in March and April (no significant difference between March and April) for both cultivars. These variations by month may be explained by the different growing conditions such as air temperature, solar light intensity, and quality in the greenhouse during the experiment. Daytime average greenhouse air temperature was 1.8 to $2.3^{\circ} \mathrm{C}$ higher in May $\left(26.1 \pm 1.5^{\circ} \mathrm{C}\right)$ than in March $\left(23.8 \pm 1.5^{\circ} \mathrm{C}\right)$ and April $\left(24.3 \pm 1.5^{\circ} \mathrm{C}\right)$ in our experiments (data not shown). Similarly, nighttime temperature inside the FR treatment boxes was higher in May $\left(19.9\right.$ to $\left.20.5^{\circ} \mathrm{C}\right)$ than in March
(16.8 to $17.4{ }^{\circ} \mathrm{C}$ ) and April $\left(17.8\right.$ to $18.1{ }^{\circ} \mathrm{C}$ ), although the difference between treatments was small $\left(0.3\right.$ to $\left.0.6{ }^{\circ} \mathrm{C}\right)$. Temperaturedependent phytochrome responses have been observed in tomato germination with warmer temperature conditions being less effective in inhibiting germination using FR (Mancinelli et al., 1966). Another possibility that induced differences among March, April, and May experiments is the "twilight effect" of lowering R/FR ratio varied between months. Our official sunset time was 1831 to $1840 \mathrm{HR}$, 1849 to $1858 \mathrm{HR}$, and 1905 to $1914 \mathrm{HR}$ during March, April, and May experimental periods, respectively, whereas all EOD treatments (including untreated control) began at 1830 HR. During twilight, when sun angle is low, a rapid change in spectral quality occurs (e.g., Hughes et al., 1984). Relatively shorter hypocotyl lengths of untreated seedlings in May than in March or April for both cultivars (Figs. 1 and 2) may be the consequence of potential differences in light quality that the untreated seedlings received before being placed inside the dark box at 1830 HR. Because we did not measure the natural light quality at the EOD, the twilight effect hypothesis needs to be confirmed with future experiments. Lund et al. (2007) demonstrated the twilight effect (or EOD light quality effect) using LEDs in their growth chamber-based study and showed that chrysanthemum plants treated with EOD-FR light at a $0.4 \mathrm{R} / \mathrm{FR}$ ratio were significantly taller than those at $0.7 \mathrm{R} / \mathrm{FR}$.

The difference observed between the cultivars in our experiment could be a result of genotype. The experiment using three different tomato cultivars, Porte, Glamour, and Ace, exhibited different germination responses at different durations of FR treatment and temperature (Mancinelli et al., 1966). 'Aloha' used in our experiment is an intraspecific hybrid rootstock (S. lycopercicum) and 'Maxifort' is an interspecific hybrid rootstock (S. lycopecicum $\times$ $S$. habrochaites). Although there is no available information on the difference in photomorphogenic response between these cultivars, 'Maxifort' is generally known as a more vigorous, fast-growing rootstock than intraspecific rootstocks such as 'Aloha' (American Takii, personal communication).

Although our non-linear regressions suggested that near saturation FR dose, estimated as $90 \%$ theoretical saturation $\left(F D_{90}\right)$, was in a range of 4.7 to $13.8 \mathrm{mmol} \cdot \mathrm{m}^{-2} \cdot \mathrm{d}^{-1}$ for 'Aloha' and 8.2 to $15.1 \mathrm{mmol} \cdot \mathrm{m}^{-2} \cdot \mathrm{d}^{-1}$ for 'Maxifort', the practical minimum FR light dose appeared to be $\approx 2$ to $4 \mathrm{mmol} \cdot \mathrm{m}^{-2} \cdot \mathrm{d}^{-1}$ for both 'Aloha' and 'Maxifort' based on our earlier analysis (Table 3). Previously reported studies using Zea mays (Gorton and Briggs, 1980), Cucumis sativus (Gaba and Black, 1985), Avena sativa, Helianthus annuus, and Vigna radiate (Gorton and Briggs, 1982) seedlings showed that saturating FR light dose levels for inhibition of anthocyanin accumulation or elongation of mesocotyl, hypocotyl, or coleoptile were between 3.6 and $10 \mathrm{mmol} \cdot \mathrm{m}^{-2} \cdot \mathrm{d}^{-1}$. This range generally agrees with our experimental results. In commercial application, target FR doses need to be selected together with the economic 
analyses and possible FR light intensity limitation of available light sources.

\section{Conclusion}

Our results showed that EOD-FR lighting could enhance hypocotyl elongation in 'Aloha' and 'Maxifort' tomato rootstock seedlings. The elongation was significantly enhanced by lowering R/FR ratio of incandescent lamps with a spectral cut filter. Both FR light intensity and duration of the treatment affected hypocotyl elongation with higher intensities and treatment durations leading to greater elongation at relatively lower FR light doses. At higher FR light doses, neither increased intensity nor duration was effective as the hypocotyl elongation response had reached saturation. The saturation response curve, expressed with a Michaelis-Menten-type model, estimated FR light doses required to achieve either $50 \%$ $\left(K_{M}\right)$ or $90 \%\left(F D_{90}\right)$ of maximum theoretical elongation being varied by growing conditions (month) and cultivar. In both EOD-FR light quality and EOD-FR dose experiments, none of the EOD-FR treatments showed reduction in stem dry weight or changes in leaf developmental stage (plastochron index) compared with the untreated control. We conclude that EOD-FR can be a potential non-chemical means to elongate rootstock seedlings, especially in the transplant industry in which a longer hypocotyl in rootstocks is desired for grafting.

\section{Literature Cited}

Blanchard, M.G. and E.S. Runkle. 2010. Intermittent light from a rotating high-pressure sodium lamp promotes flowering of long-day plants. HortScience 45:236-241.

Blom, T.J., M.J. Tsujita, and G.L. Roberts. 1995. Far-red at end of day and reduced irradiance affect plant height of Easter and Asiatic hybrid lilies. HortScience 30:1009-1012.

Decoteau, D.R. and H.H. Friend. 1991. Growth and subsequent yield of tomatoes following end-ofday light treatment of transplants. HortScience 26:1528-1530.

Decoteau, D.R., M.J. Kasperbauer, D.D. Daniels, and P.G. Hunt. 1988. Plastic mulch color effects on reflected light and tomato plant growth. Sci. Hort. 34:169-175.

Erickson, R.O. and F.J. Michelini. 1957. The plastochron index. Amer. J. Bot. 44:297-305.

Fredericq, H. 1964. Conditions determining effects of far-red and red irradiations on flowering response of Pharbitis nil. Plant Physiol. 39:812-816.

Gaba, V. and M. Black. 1985. Photocontrol of hypocotyl elongation in light-grown Cucumis sativus L. Planta 164:264-271.

Gorton, H.L. and W.R. Briggs. 1980. Phytochrome responses to end-of-day irradiations in lightgrown corn grown in the presence and absence of Sandoz 9789. Plant Physiol. 66:1024-1026.

Gorton, H.L. and W.R. Briggs. 1982. A survey of the reciprocity characteristics of responses to end-of-day irradiations in oat, sunflower, and mung bean. Plant Cell Environ. 5:423-429.

Hatt Graham, H.A. and D.R. Decoteau. 1997. Young watermelon plant growth responses to end-of-day red and far-red light are affected by direction of exposure and plant part exposed. Sci. Hort. 69:41-49.

Hendricks, S.B. and H.A. Borthwick. 1967. The function of phytochrome in regulation of plant growth. Proc. Natl. Acad. Sci. USA 58:21252130.

Hendricks, S.B., W.L. Butler, and H.W. Siegelman. 1962. A reversible photoreaction regulating plant growth. J. Phys. Chem. 66:2550-2555.

Hughes, J.E., D.C. Morgan, P.A. Lambton, C.R Black, and H. Smith. 1984. Photoperiodic time signals during twilight. Plant Cell Environ. 7:269-277.

Kasperbauer, M.J. and D.E. Peaslee. 1973. Morphology and photosynthetic efficiency of tobacco leaves that received end-of-day red or far red light during development. Plant Physiol. $52: 440-442$
Kubota, C., M.A. McClure, N. Kokalis-Burelle, M.G. Bausher, and E.N. Rosskopf. 2008. Vegetable grafting: History, use, and current technology status in North America. HortScience 43:1664-1669.

Lund, J.B., T.J. Blom, and J.M. Aalyng. 2007. Endof-day lighting with different red/far-red ratios using light-emitting diodes affects plant growth of Chrysanthemum $\times$ morifolium Ramat. 'Coral Charm'. HortScience 42:1609-1611.

Mancinelli, A.L., H.A. Borthwick, and S.B. Hendricks. 1966. Phytochrome action in tomato-seed germination. Bot. Gaz. 127:1-5.

Martinez-Garcia, J.F., C.M. Santes, and J.L. GarciaMartinez. 2000. The end-of-day far-red irradiation increases gibberellin $\mathrm{A}_{1}$ content in cowpea (Vigna sinensis) epicotyls by reducing its inactivation. Physiol. Plant. 108:426-434.

Moe, R., J. Xiong, G.G. Patil, S. Torre, and E. Thingnaes. 2003. Effect of end-of-day far red light on the responses to fluctuating day/night temperatures in cucumber and Arabidopsis. Acta Hort. 624:279-285.

Naganati, A., J. Chory, and M. Furuya. 1991. Phytochrome B is not detectable in the hy3 mutant of Arabidopsis, which is deficient in responding to end-of-day far-red light treatments. Plant Cell Physiol. 32:1119-1122.

Olsen, J.E. and O. Junttila. 2002. Far red end-ofday treatment restores wild type-like plant length in hybrid aspen overexpressing phytochrome A. Physiol. Plant. 115:448-457.

Rajapakse, N.C., M.J. McMahon, and J.W. Kelly. 1993. End of day far-red light reverses height reduction of chrysanthemum induced by $\mathrm{CuSO}_{4}$ spectral filters. Sci. Hort. 53:249-259.

Sager, J.C., W.O. Smith, J.L. Edwards, and K.L. Cyr. 1988. Photosynthetic efficiency and phytochrome photoequilibria determination using spectral data. Trans. ASAE 31:1882-1889.

Siegelman, H.W., B.C. Turner, and S.B. Hendricks. 1966. The chromophore of phytochrome. Plant Physiol. 41:1289-1292.

Xiong, J.Q., G.G. Patil, and R. Moe. 2002. Effect of DIF and end-of-day light quality on stem elongation in Cucumis sativus. Sci. Hort. 94: 219-229. 